\title{
The role of local theories: teacher knowledge and its impact on engaging students with challenging tasks
}

\author{
Jeffrey Choppin
}

Received: 4 March 2011 /Revised: 4 March 2011 /Accepted: 4 March 2011

(C) Mathematics Education Research Group of Australasia, Inc. 2011

\begin{abstract}
This study explores the extent to which a teacher elicited students' mathematical reasoning through the use of challenging tasks and the role her knowledge played in doing so. I characterised the teacher's knowledge in terms of a local theory of instruction, a form of pedagogical content knowledge that involves an empirically tested set of conjectures situated within a mathematical domain. Video data were collected and analysed and used to stimulate the teacher's reflection on her enactments of an instructional sequence. The teacher, chosen for how she consistently elicited student reasoning, showed evidence of possessing a local theory in that she articulated the ways student thinking developed over time, the processes by which that thinking developed, and the resources that facilitated the development of student thinking. Her knowledge informed how she revised and enacted challenging tasks in ways that elicited and refined student thinking around integer addition and subtraction. Furthermore, her knowledge and practices emphasised the progressive formalisation of students' ideas as a key learning process. A key implication of this study is that teachers are able to develop robust knowledge from enacting challenging tasks, knowledge that organises how they elicit and refine student reasoning from those tasks.
\end{abstract}

Keywords Curriculum · Local theory · Challenging tasks · Teacher knowledge · Instructional practices

\section{Introduction}

Teachers in many countries engage in the "shallow teaching syndrome" (Vincent and Stacey 2008), which includes heavy use of textbooks and the cluster of lesson features that includes "low procedural complexity of problems, high proportion of

J. Choppin $(\bowtie)$

Department of Teaching and Curriculum, The University of Rochester, Dewey Hall 1-160K,

Box 270425, Rochester, NY 14627, USA

e-mail: jchoppin@warner.rochester.edu 
repetition, and absence of mathematical reasoning in classroom discourse" (p. 83). In part, this relates to the characteristics of textbooks, but it also relates to engrained teacher practices. Sullivan et al. (2009) note that "it seems to us that there are many interesting tasks available to teachers, yet it does not appear that teachers are taking advantage of these tasks in an effective way" (p. 86).

The "shallow teaching syndrome" is a confluence of at least three related phenomena. First, teachers in many countries rely extensively on textbooks or worksheets as the primary source of instructional tasks (Hiebert et al. 2003). Second, many of the textbooks on which the teachers primarily draw are designed to focus on the acquisition of basic skills through repetition of well-defined problems. Schoenfeld (2006) noted that the perspective reflected in these textbooks suggests that "learning is the accumulation of knowledge; that practice solidifies mastery; and that knowledge is demonstrated by the ability to solve particular (well-studied) classes of problems" (p. 15). Third, even when teachers are presented with challenging tasks, they often are at a loss to enact them in ways that might elicit and develop students' mathematical reasoning (Stein et al. 1996; Sullivan et al. 2009).

In the U.S., a number of curricula have been developed that depart from conventional notions of curricula and that build from decades of research in the cognitive sciences of how children learn mathematics (Schoenfeld 2006). Although these curricula were intended to support teachers' efforts to engage students with challenging tasks, there has been little evidence that simply introducing these curricula changes teachers' practices (cf. Collopy 2003; Remillard and Bryans 2004), in part because they "require teachers to be more than presenters of content; they require teachers to actively and continuously interact with students' construction of mathematical concepts and ways of reasoning" (Confrey et al. 2008 , p. 107). Consequently, it is likely that teachers need to develop new forms of knowledge in order to enact the tasks in the materials in ways that elicit and build from students' mathematical reasoning.

There has been much discussion about the kinds of knowledge that impact teachers' ability to engage children in ways that help them learn with understanding, with a particular focus on the role of pedagogical content knowledge (PCK) (e.g., Grossman 1990; Magnusson et al. 1999; Shulman 1986), which Gess-Newsome (1999) describes as "the transformation of subject matter, pedagogical, and contextual knowledge into a unique form - the only form of knowledge that impacts teaching practice" (p. 10, author's italics). More recently, Hill et al. (2008) have attempted to refine notions of PCK into various components, including situating PCK in particular mathematical domains. They state, for example, that knowledge of content and students is "used in tasks of teaching that involve attending to specific content and something particular about learners, for instance, how students typically learn to add fractions and the mistakes or misconceptions that commonly arise during this process" (p. 375). Thus, the most relevant knowledge is conceived as unique to teaching (in fact transformed while teaching) and has some explanatory power with respect to how students learn in particular domains. The research on teacher knowledge, however, has primarily shown an association between forms of PCK and student learning (e.g., Hill et al. 2005), with a need to further elaborate how PCK functions to help teachers organise instruction to elicit and refine student reasoning through the use of challenging tasks. 
This study explores the case of a teacher who enacted challenging tasks from one of the innovative U.S. curricula. The study explores the extent to which the teacher elicited students' mathematical reasoning through the use of challenging tasks and the role her knowledge played in doing so. Specifically, I explore the ways the teacher elicited student reasoning during enactments of challenging tasks around integer addition and subtraction.

\section{Research questions}

The research questions that guided this study were:

1. To what extent was the teacher able to elicit and build from student reasoning through the use of challenging tasks?

2. What knowledge was evident in the teacher's practices and reflection on those practices, particularly with respect to her understanding of how student thinking developed across an instructional sequence related to integer addition and subtraction?

3. How did the teacher's knowledge help her to use challenging tasks to elicit and build from students' mathematical reasoning?

\section{Framework}

I explore teacher knowledge in terms of a local theory of instruction as a form of PCK situated within a particular instructional sequence. As briefly discussed above, PCK can be considered a form of knowledge that is highly situated, both within the practice of teaching and within mathematical domains. Local theories are similarly conceived as situated close to practice and to specific mathematical domains, and are typically associated with particular instructional sequences. To describe local theories of instruction, I turn to three primary sources: design research (e.g. diSessa and Cobb 2004), lesson study (Lewis et al. 2006), and realistic mathematics education (RME) (Gravemeijer 1994, 2004; Van den Heuvel-Panhuizen 2003).

For the purposes of this paper, I consider a local theory of instruction to be an empirically tested set of conjectures about how students learn in a specific mathematical domain, or what diSessa and Cobb (2004) call domain specific learning processes, with respect to a particular instructional sequence. The testable conjectures include both the processes by which students learn in a particular mathematical domain and the resources that influence or support those processes (Cobb et al. 2003). In this study, the local theory of instruction involved the specific mathematical domain of integer addition and subtraction and an instructional sequence associated with a set of curriculum materials. Following Carpenter et al. (2004), I characterise an instructional sequence as both a sequence of tasks and the potential learning trajectories that might emerge from student engagement with that sequence.

Local theories are pragmatic, situated, and empirical, reflecting their instrumental emphasis and their basis in iterative cycles of enactment, reflection, and revision 
around instructional sequences (diSessa and Cobb 2004). As a result of local theories' pragmatic focus, diSessa and Cobb note that such theories often fall short of offering a full explanatory theory, functioning instead closer to the level of pedagogical conjecture. Furthermore, given the situated and pragmatic nature of these theories, there may be tacit features of the theory that are embedded in local structures in ways that hinder their transparency and portability (Lewis et al. 2006). The purpose of developing a local theory, consequently, may not be about developing broad explanatory value, but rather to develop capacity at the local level (e.g., in a teacher or group of teachers). Lewis, Perry, and Murata use the term local proof route to denote that in a local versus a general theory the "innovation may depend on local capacity and be designed to build it" (p. 7).

The key features of local theories of instruction that will be explored in this study are summarised in Table 1. First, a local theory provides an indication of the potential learning trajectories that might emerge from engaging with a task sequence. Second, a local theory indicates the learning processes, connecting perhaps to broader principles but situating those principles in the context of a particular instructional sequence or mathematical domain. Third, a local theory identifies resources and describes how those resources facilitate learning within a mathematical domain.

The principles articulated in the realistic mathematics education perspective reiterate features of local theories described above, notably the empirical and situated nature of the theories and the focus on instructional sequences, but also provide some specific characteristics of instructional sequences that serve as the foci of local theories. There are two implications of the RME formulation of local theories. First, Gravemeijer's (2004) articulation of local instruction theories emphasises the notion that instruction should elicit and build from students' informal or pre-formal thinking, which is progressively refined toward more formal mathematical representations and terminology, in a process of progressive formalisation. Gravemeijer states that "what is needed is a form of instructional design supporting instruction that helps students to develop their current ways of reasoning into more sophisticated ways of mathematical

Table 1 Features of local theories of instruction

Feature Description

How student thinking develops over time

The processes by which student thinking develops

The resources that facilitate the development of student thinking
Description of learning trajectories that might emerge from engaging with an instructional sequence; i.e., the ways that student thinking develops over time with respect to key ideas and concepts, including descriptions of the pre-formal and formal terminology, models, representations, and strategies

How the processes of formalisation work with respect to a particular instructional sequence (i.e., description of the learning principles that guide the development of student learning)

The tasks, representations, models, tools, or other resources that afford or constrain student learning across the instructional sequence 
reasoning" (p. 106). Engaging students in progressive formalisation provides educators opportunities to learn from students' informal or pre-formal thinking as a starting point for designing curriculum and instruction (Van den Heuvel-Panhuizen 2008), a point reiterated by Gravemeijer, who states:

Older design principles take as their point of departure the sophisticated knowledge and strategies of experts to construe learning hierarchies... The result is a series of learning objectives that can make sense from the perspective of the expert, but not necessarily from the perspective of the learner. (p. 106)

The notion of progressive formalization suggests that tasks early in an instructional sequence should involve situations that are authentic or experientially real to students, in order to recruit their pre-formal experiences to a mathematical context (Van den Heuvel-Panhuizen 2003). Similarly, these early tasks should provide opportunities to develop and gain experience with tools and models that can serve as analogues for subsequent activity. As the instructional sequence proceeds, the students' initial ideas and experiences are refined toward more sophisticated and formal forms. Over the instructional sequence, students engage in cycles of conjecturing, refining, and formalising in a collective context so that students learn from each other's ideas and practices. Table 2 summarises the progression of student activity across an instructional sequence according to the RME perspective.

The features of local theories of instruction summarised in Table 1 are tightly related to the features of instructional sequences summarised in Table 2. First, the phases implicated in Table 2 constitute the outlines of the learning trajectories that are associated with a local theory. Second, the learning processes related to a particular domain can be found within each of the three phases in Table 2. For example, eliciting students' informal reasoning and collectively discussing the ideas represented in that reasoning constitute an initial process for developing more refined reasoning in a domain. Similarly, reflecting on and revising conjectures are important disciplinary processes in the learning of mathematics (Lampert 1990). Third, the models and representations in the middle phase of Table 2 are examples of

Table 2 Progression across instructional sequence in RME

\begin{tabular}{|c|c|}
\hline Feature & Description of feature \\
\hline $\begin{array}{l}\text { Eliciting students' informal } \\
\text { reasoning }\end{array}$ & $\begin{array}{l}\text { There is an emphasis on early informal experiences in } \\
\text { which students' prior forms of mathematical reasoning } \\
\text { are elicited, which helps the teacher to assess student } \\
\text { thinking and provides a basis on which to build } \\
\text { subsequent reasoning. }\end{array}$ \\
\hline $\begin{array}{l}\text { Developing models and } \\
\text { representations }\end{array}$ & $\begin{array}{l}\text { Students have early sense-making experiences with models } \\
\text { and representations in ways that support their efforts to } \\
\text { develop more formal representations and to make sense of } \\
\text { key mathematical concepts. }\end{array}$ \\
\hline $\begin{array}{l}\text { Generating and refining } \\
\text { conjectures }\end{array}$ & $\begin{array}{l}\text { There is a consistent emphasis on the iterative process of } \\
\text { developing and refining conjectures over the instructional } \\
\text { sequence, with an eye toward formalising the conjectures. }\end{array}$ \\
\hline
\end{tabular}


resources that facilitate learning in a particular domain. Consequently, a teacher's understanding of the features of instructional sequences, as noted in the RME perspective, is linked to the development of local theories in given mathematical domains.

\section{Context}

In this section, I describe the context in which the case is situated, with respect to the teacher, the students, and the curriculum materials.

The teacher

The teacher, Ms. Clarke, ${ }^{1}$ was a participant in a larger study of 10 teachers' use of challenging curriculum materials. Ms. Clarke was selected because she had the highest rating of the 10 teachers in an analysis of the classroom discourse in terms of the extent to which she engaged students in conceptual discourse around challenging tasks. Ms. Clarke, a teacher with about 20 years of teaching experience, was observed teaching a $6^{\text {th }}$-grade class (mostly 12 -year-olds). She had many years of experience teaching with the curriculum materials, including pre-publication drafts of the materials. She had received numerous hours of curriculum-specific professional development, including sessions at the development site with personnel closely associated with the design of the materials, and regularly conducted curriculum-specific professional development in local districts. Ms. Clarke had taught the instructional sequence in which she was observed only one time prior to the enactment reported below, though she had taught a prior version of the sequence several times.

The students

Most of the $6^{\text {th }}$-grade students observed for this study had been taught with Investigations (TERC 1998), a primary school curriculum similar to the materials used in the $6^{\text {th }}$ grade, for grades 1 to 5 . Consequently, they were accustomed to engaging with challenging tasks and with communicating their solution strategies. These students were "accelerated," meaning they were engaging with $7^{\text {th }}$-grade content as $6^{\text {th }}$ graders. The district in which the school was located was noted for its high scores on standardised achievement tests, so these students had generally performed well in prior mathematics classes and on standardised achievement tests relative to other students in their school and in the local geographical area. Although these students had prior experiences with similar curriculum materials, their engagement in Ms. Clarke's class cannot simply be attributed to their prior experiences with such materials. Students observed in $8^{\text {th }}$ grade classes in the same school, and who consequently had two more years of experience with this type of curriculum, engaged with tasks in much less demanding ways than Ms. Clarke's students.

\footnotetext{
${ }^{1}$ The names of the teachers and students are pseudonyms.
} 
The curriculum materials

The teachers were using materials from the Connected Mathematics Project (CMP) curriculum (Lappan et al. 1998, 2006), which was designed as a problembased curriculum using funds from the U.S. National Science Foundation (Lappan and Phillips 2009). The curriculum materials are markedly different from typical curricula found in the U.S. in that they emphasise the development of procedural and conceptual competency through solving demanding tasks. Each CMP unit is divided into four or five investigations, each of which consists of a task situation or context that serves to organise the investigation. Each investigation begins with an initial problem that focuses on the key mathematical concepts, followed by a number of related problems. The investigations are intended to follow a launchexplore-summary format. The launch serves to familiarise students with the context and the mathematics as a means of priming student activity in the subsequent exploration, in which students engage with a task that can be approached in multiple ways. The summary portion allows for various solutions to be compared and for the teacher to emphasise the important mathematical aspects of the tasks. The CMP materials differ from more conventional texts in that they are comprised largely of tasks that are designed to be implemented at a high level of cognitive demand (Cai et al. 2009) and that require substantial amounts of student justification and explanation (Stylianides 2009).

\section{Methods}

Below, I describe the data collection and analysis methods with respect to the teacher's instructional practices, her knowledge, and the impact of her knowledge on student engagement with complex tasks.

\section{Data collection}

The research team videotaped Ms. Clarke teaching the Accentuate the Negative unit over two years, with nine 80-minute lessons the first year and seven 80-minute lessons the second year. The team created Unit Sets using the video data, modifying the teaching set methodology (Simon and Tzur 1999; Cobb et al. 2009), which involves recording multiple lessons and using specific events or practices observed in those lessons as the basis of an audio-recorded interview. In each of the two years (2008 and 2009), I selected ten to twelve brief episodes from the video data and used them to elicit reflections about specific tasks, instructional practices, and student thinking within and across tasks, and justifications for adaptations of the curriculum materials. In 2009, in addition to the post-unit video-stimulated interview (VSI) described above, I also conducted a pre-unit interview in which I asked the teacher questions about the overall goals of the unit, the challenges student were likely to encounter, and the resources in the unit that helped students learn. In 2010, I conducted a joint interview (JI) with Ms. Clarke and her planning partner, Ms. Praeger, in which I asked them to reflect on the 2010 enactment of Accentuate the Negative. 


\section{Data analysis}

The video data were analysed to characterise the extent to which the teacher elicited and built from student reasoning. As noted above, a separate analysis showed that Ms. Clarke consistently engaged students in mathematical reasoning, with all 15 coded lessons (from two different curriculum units) scoring in the highest category, meaning there were at least four occasions per lesson in which Ms. Clarke pressed students to explain their reasoning and at least four occasions when students provided reasoning for their answers. Usually, these events occurred far more frequently than four times per lesson. Consequently, the analysis for this study focused on how student reasoning was elicited and developed across the instructional sequence, following the characteristics of instructional sequences noted in Table 2. This analysis focused strictly on episodes of whole-class discussion in only one of the two enactments (2009), so that the episodes presented below are from the same classroom.

The interview data were analysed to characterise the teacher's knowledge with respect to the instructional sequence. Her knowledge was analysed with respect to features of local theories discussed above, notably the ways she articulated (1) how student thinking developed over time, (2) the processes by which that thinking developed, and (3) the resources that facilitated the development of student thinking. Data from the interviews that corresponded to each of these three categories were merged and then analysed for themes within categories to develop an understanding of the characteristics of the teacher's local theory.

\section{Description of the instructional sequence}

The instructional sequence described below includes only the key tasks and resources in the sequence, as discussed by Ms. Clarke in the interviews and as noted by the author in his analysis of the classroom videos. Less relevant tasks, including homework problems and some of the tasks used to begin each lesson, were excluded. The tasks primarily derived from the student text, but there were some revisions of those tasks and a notable task introduced by Ms. Clarke that was not found in the student text. The discussion of the sequence focuses on eight tasks. In Table 3, I divide the tasks according to the three features of instructional sequences identified in Table 2, which function for the most part to distinguish three chronological phases of the sequence. For example, the opening discussion around properties of integers, in addition to the Math Fever and Sauna problems, constitute a phase in which students' reasoning based on prior experiences with integers was elicited. The students' activity in this phase was based in contexts that allowed students to informally engage in integer operations and to begin the process of developing and refining conjectures. In the subsequent phase, marked mostly by the What's the Change and Chip Board problems, there was a more explicit focus on developing representations and models that were then used in subsequent tasks. In the third phase, students focused on patterns in the operations they had carried out earlier in the sequence in order to develop conjectures around rules for integer addition and subtraction. 
Table 3 Sequence of tasks for adding and subtracting integers

Opening discussion around properties of integers

Math Fever and Sauna problems

What's the Change

Chip Board problems

Eliciting and refining conjectures Patterns for addition and subtraction Developing efficient strategies

\author{
Elicited informal ideas about integer addition and \\ subtraction, connecting to students' prior \\ knowledge and pre-formal ideas \\ Development of number sentences as key \\ representation and the introduction of chip \\ board model as a complement to the number \\ line. These tools and representations supported \\ the emergence of other practices \\ Tasks provided opportunities to build on and \\ refine conjectures for integer addition and \\ subtraction, with the goal of developing efficient \\ strategies that made sense to students and that \\ utilised the models and representations developed \\ earlier in the sequence
}

Below, I describe results to show how Ms. Clarke enacted the instructional sequence and the knowledge that guided her enactment of the instructional sequence. I then relate the enactment of the instructional sequence to the ways in which Ms. Clarke's knowledge had features of a local theory of instruction.

\section{Results}

I discuss the results by focusing on Ms. Clarke's knowledge of the instructional sequence. I incorporate episodes from the video data to illustrate how Ms. Clarke's enactment displayed the features of instructional sequence outlined in Table 2 and how the characteristics of Ms. Clarke's local theory of instruction were manifest in classroom interactions. I organise the presentation of results to roughly follow the progression of the instructional sequence, alluding to characteristics of the local theory and of the instructional sequence where appropriate.

\section{Eliciting students' informal reasoning}

Ms. Clarke used the tasks early in the sequence to elicit students' reasoning around integers, in part to begin the process of collectively discussing ideas and to build from students' prior experiences with integers. She stated:

These opening discussions are to help students tap into what they already know... to help them draw upon that as a basis for a foundation... what I want them to do in those beginning discussions is make connections ... to either problems that they've done before or contexts. (VSI, August 28, 2009)

An episode (from January 14, 2009) from the first task in the sequence illustrates the free-ranging nature of the beginning discussions and how Ms. Clarke used them 
to get a range of ideas on the table. The episode below follows a request by Ms. Clarke to share ideas about the characteristics of integers.

1. Student1: It's a whole number and its opposites

2. S2: It's less than one.

3. Chris: Integers! "The whole numbers and their opposites" [reading from the book]. "Zero is an integer, but is neither positive nor negative. Negative 4 to 4 are shown at the number line below."

[The students continued to give their ideas about integers for 13 turns.]

16. T: Rob, what are you thinking?

17. Rob: Well, integers, when Chris read the definition, whole numbers and their opposites. So, it means like 4 and negative 4 are opposites. One is 4 over zero and one is four under zero.

[A student subsequently gave an example of owing money and another student gave an example of temperature, citing the day's temperature of negative 5 degrees.]

26. T: Karen?

27. Karen: An integer is a negative and a positive number sometimes.

28. S: Cause it says "the integers from negative 4 to 4 are shown on the number line here."

29. T: John?

30. John: It can't be both a negative and a positive number.

31. Jawad: I'm guessing it's like two numbers. One negative and one positive.

32. T: So, what do you think about what Karen said and that John and Ahmad were commenting on? Can a number be both positive and negative?

33. S: Zero is both positive and negative?

34. T: Rob?

35. Rob: 4 and negative 4 are the same number, almost in a different form. Almost in parallel universes.

Ms. Clarke then oriented the discussion toward situating the numbers on the number line, getting students to note that the -4 and 4 are the same distance from zero but that they are not the same number. In this discussion, the idea of "distance from zero" was raised, and Ms. Clarke emphasised the idea but not terminology of absolute value, which was typical of her practice of refraining from formalising terminology and strategies early in the sequence. In the episode, Ms. Clarke asked students to express their reasoning and to comment on other students' reasoning, providing opportunities for students to make connections to their prior knowledge and to begin more formal consideration of the properties of integers.

Ms. Clarke also noted the value of allowing students in the initial tasks to engage in pre-formal activities in order for them to make sense of integers. She stated that "I want to allow kids time and context and problems that allow them to mess around and make sense of integers ... to have time to build ... this foundation ... to make sense of integers in different contexts or different problems" (VSI, August 28, 2009). An episode from the Math Fever task early in the sequence (January 16, 2009) 
shows how the number sentences generated from this context launched a discussion around integer addition and subtraction. It is important to note in the episode that Ms. Clarke avoided discussing formal rules. In the Math Fever game context, players lose or gain points according to whether they correctly answer questions and students are asked to generate number sentences to show how a particular score was reached.

36. Jawad: When he says it's negative 150 , there's no point value that's negative 150. [Jawad is referring to a number sentence on the board that refers to a case in which a team lost 150 points.]

37. T: What does it mean, "negative 150"?

38. Jawad: Well, it still means minus 150 .

[Clarke and Jawad then clarified what negative 150 meant in the game show context.] $\cdots$

44. Jawad: But to say "plus negative 150?"

45. T: So that's a different way of thinking about it.

46. Aaron: My dad says there is no subtraction, there's only addition. So, if you were saying "500 and negative 250," that would equal 250 , because there's only addition in the equation.

47. T: So, you're saying 500 plus negative 250 . [writing down $500+-250=250$ on the board]

48. Aaron: But you don't write "500-250."

49. Rob: If you subtract two negative numbers, you are going to add because when a negative number, instead of subtracting, you're also subtracting again, because you're using a negative number, so then you're actually adding.

50. T: Hang on to those thoughts. Wade?

51. Wade: I think saying 500 plus negative 250 is just preference.

52. John: About what Rob was saying, you can't, if you have a positive number more than the number you're subtracting, you would not say minus negative because the number you're subtracting is less than the number you have before, therefore if you subtract it, you would still have a positive number. You would never be able to write minus a negative.

In the episode, the students provided a series of conjectures about integer addition and subtraction, some of which were based in prior conversations or experiences. The discussion exemplified Ms. Clarke's goals of allowing students to "mess around" with integers, using the contexts to generate situations and number sentences that could be represented by either addition or subtraction. She did not attempt to formalise the ideas raised by the students, and instead emphasised the sense-making aspects of the early tasks, allowing students to state claims without directly evaluating them.

Ms. Clarke described the development of language as a key learning process throughout the instructional sequence, which was evident in the interviews and in the episodes presented above. She stated that a goal of the early discussions was "to problematise the language around [integer operations] so that they could talk more clearly ... around what's happening" (VSI, June 4, 2008). In the episodes above, Ms. Clarke focused students on the consequences of their language choices. For example, she called attention to Karen's claim about the properties of integers not by 
correcting it, but by asking other students to comment on the claim. Similarly, in her interaction with Jawad, she asked him to clarify what it meant to add "negative 150" and concluded the interaction with a non-evaluative comment when he connected "minus 150 " to "plus negative 150." In another example, during a discussion early in the sequence (January 14, 2009), she asked students to consider what was meant by the "highest negative" number to clarify the distinction between the negative number closest to zero and the negative number with the highest absolute value.

In terms of the elements of the local theory manifest in Ms. Clarke's reflection on the initial phase of the instructional sequence, she indicated a sense of the learning trajectory when she stated that an aim of the initial tasks was to refrain from formalising too early because there would be subsequent opportunities to do so. She stated, for example, that her goal was "trying not to go too far knowing that they might not all be ready and knowing that there are going to be future experiences based on the progression of the unit" (VSI, June 4, 2008). As noted above, she recognised the contexts as resources to help the students think about integers in ways that drew on their prior experiences.

\section{Developing models and representations}

Ms. Clarke described the role of models and representations in developing student reasoning beyond the informal phase. She described how these models and representations served as resources in terms of coordinating the discussion between number sentences and operations and in terms of establishing the basis of claims made about integer addition and subtraction. For example, early in the sequence Ms. Clarke focused on developing number sentences that could be subsequently used to make conjectures about the relationship between integer addition and subtraction. She also discussed the role of the number line and chip board models in allowing students to develop and justify conjectures. These examples are discussed in more detail below.

Number sentences Ms. Clarke, in collaboration with her fellow $6^{\text {th }}$-grade teacher Ms. Praeger, adapted the Temperature Change task to emphasise writing number sentences that represented situations in which the students knew the starting and ending temperatures and were asked to find the change in temperature. In their initial enactment of the task, the students had focused on computing the change without first representing the situation. The teachers felt that doing so obscured the relationship to integer versus whole-number operations. For example, if students were given a starting temperature of 20 and a final temperature of negative 10 degrees, they might simply calculate the difference to be 30 degrees, possibly by adding 20 and 10. Instead, Ms. Clarke wanted them to write $20+\ldots=-10$, which helped to facilitate discussions around the connection between $20-\overline{30}$ and $20+-30$. The goal, as Ms. Clarke stated, was to have students "write multiple number sentences that represent the same situation so that we can draw on those examples later when they're trying to make their generalisations about how the operations work" (VSI, August 28, 2009). In an episode in which the problem described above was discussed, for example, the students got into a discussion about whether 20-30 showed that the change was negative in the same way that $20+-30$ showed the change was negative. 
Number line and chip board models Ms. Clarke discussed how the number line and chip board models served two purposes. First, the models helped students to develop an understanding of integer operations grounded in actions around the models, and, second, students referenced the models when presenting evidence for subsequent conjectures. Ms. Clarke felt, however, that students needed informal experiences with the models in order to develop an understanding of how to use the models as tools. She stated for example that it was important to get students "to talk about the number line and make sense of it and mess around with it, (e.g.) where is big or where is small or what's happening over here with these negative numbers" and emphasised the number line early because "I knew the number line was going to be used as a model later in terms of adding or subtracting" (VSI, June 4, 2008).

She described important features of each model. She noted, for example, that an important difference between the chip board and number line models was that the chip board helped connect integer operations to whole number operations. Ms. Clarke stated that chip board was "closer to how they've thought about addition and subtraction with whole numbers in terms of adding on or taking away, whereas in a number line it's movement" (VSI, August 28, 2009). She discussed how the number line helped students to connect operations to the number sentences, and that this connection was vital to developing subsequent generalisations. The process of using the number line to connect operations to number sentences was illustrated in a classroom episode in which students discussed the number sentence $8+-7=1$. Ms. Clarke, in reflecting on the episode, stated that in this problem the students used the number line "as a tool to develop their facility with starting at 8 and adding negative 7 and looking at that answer and writing a number sentence so that they would then be able to generalise that at some point" (VSI, August 28, 2009). In the episode (January 23, 2009), Ms. Clarke focused the students on how the different ways of writing the number sentence mapped onto actions on the number line.

53. T: So, the first one. Start at 8 , add -7 . Okay Wade?

54. Wade: I got 8 minus 7 equals 1 .

55. T: Okay, so what happened on a number line?

56. Wade: Umm, umm, I don't know how to explain how it happened. It went left on the number line...

57. T: Starting at what?

58. Wade: Starting at 8 .

59. T: Okay, 8 is the start

60. Wade: and...

61. T: And it went left, why did it go left?

62. Wade: Because you're subtracting, you're adding a number to it.

63. T: It doesn't say subtract, it says add.

64. Wade: I added negative 7, which did the same thing as subtracting 7 to a number.

65. T: "Which is the same thing as subtracting seven," so it sent you left. So this was "adding a -7 ." Can I write this down as another number sentence? [Writing down 8+-7]

66. S: Yes! 
67. T: Adding a negative 7 or subtracting 7 . They both sent you left on a number line.

The episode continued with a student who described a number sentence in which she switched the addends, which she claimed generated an equivalent number sentence. Ms. Clarke represented the new number sentence with an arrow starting at -7 and moving 8 units to the right to show that it ended up at the same point as Wade's number sentence. The discussion ended with a student saying that when adding 8 and -7 you are performing the operation $8-7$. In this episode, Ms. Clarke focused students on the actions represented by number sentences and the connections between the number sentences, the number line, and the operations used to arrive at an answer. In doing so, she provided opportunities for students to reason about integer operations and made a potentially simple task challenging.

In terms of the characteristics of a local theory, Ms. Clarke articulated how models and representations served as resources in helping to develop students' understanding. Specifically, she described how these resources supported subsequent generalisations and grounded student thinking in actions. Furthermore, she articulated the processes by which students developed an understanding of these resources in ways that proved useful to students.

Generating and refining conjectures

Ms. Clarke, in collaboration with Ms. Praeger, introduced a task that was designed to focus students on the conjectures they had developed in the early part of the sequence. For both addition and subtraction, the teachers had the students record their conjectures, from which the teachers selected a sample to collectively pose to the students to discuss their accuracy. In Ms. Clarke's class, for example, the students spent 60 minutes (February 4, 2009) reflecting on the conjectures around subtraction. Ms. Clarke stated that she added the task because the early part of the sequence did 'not formally or explicitly draw kids' attention to what they were actually doing and help them to draw generalisations" (Joint Interview [JI], March $25,2010)$. The goal of the emphasis on student conjectures was to "support [the students] towards writing ... about what they're noticing” (JI, March 25, 2010), as a precursor to developing efficient yet comprehensive strategies.

These discussions were evidence of Ms. Clarke's emphasis on sense-making and on helping students to progressively refine their thinking. Even though at this point the students had spent two weeks thinking about integers, it was clear from the discussions around the conjectures that students still held a variety of misconceptions. In the episode below (February 4, 2009) Amelia, for example, spontaneously raised a new conjecture, which became the focus of the discussion.

68. Amelia: Or you could just say "when you're subtracting a positive or negative number, you can just move the numbers toward zero instead of just going right or left."

69. T: Are you always going toward zero? That's a great question.

70. S: No!

71. S: Unless you're farther from zero, but you're still going that direction.

72. S: No, [inaudible], you are still going to the right. 
73. S: Yeah, when you go below zero, you're not going to ...

[Ms. Clarke then introduced the example of 10-(-3), which she connected to the chip board model. Aaron described how using the chip board would show that the answer is 13, and Ms. Clarke guided the class through how this result could be achieved on the chip board. Another student raised the example of $-3-6$, which again would lead to a result farther from zero than the starting value. Below, the episode continued when a student tried to repair Amelia's conjecture.]

107. S: If you're subtracting a negative number minus a negative number, then you're always moving toward zero. Actually, couldn't you say, "if you're subtracting" ... yeah, if you say "that the opposite for positives, like a positive number minus a positive number, then you're moving toward zero."

108. T: So, we could fix your statement, Amelia, we couldn't say it for everything. Sharon?

109. Sharon: It's not true.

110. T: Which one?

111. Sharon: You always move toward zero. Because, if you have like 11 and you subtract 23, once you get past zero, you're going in the opposite direction from zero.

In this episode, the discussion around Amelia's conjecture began with some tentative reactions, to which Ms. Clarke and another student responded by providing examples that contradicted Amelia's conjecture. Another student repaired Amelia's conjecture and then Sharon provided an example where the action of the operation on the number line crossed zero, which was a different case than the other two counterexamples. The episode showed that Ms. Clarke provided opportunities for students to engage in mathematical reasoning, both by presenting conjectures and critiquing the conjectures of others, to facilitate the process of gradual refinement and formalisation.

In a second episode from later in the same class session, the students were considering the conjecture "When you are subtracting negatives you will always get positives." The episode illustrated the idiosyncratic and formative nature of students' sense-making, as well as their opportunities to reason from challenging tasks.

112. Karen: It depends on how hard the numbers are, like negative 100 minus negative 1 , equals negative 99 , which is not positive. But when you do like negative 2 minus negative 5 it's going be 3 and that's positive.

113. T: You're going to get a positive answer or a negative answer. Karen, keep going.

114. Karen: If the first number is larger than the second, you're going to get a negative, and if it's smaller...

115. T: Wait, if the first number is ... larger than the second?

116. Karen: Without the negative ... larger than the second, you're going to get a negative number, but if the first number is smaller than the second number, you're going to get a positive.

117. S: What?

118. T: Yeah, you've got to be careful of your language there, because, "without the negative." You're close. 
[A student offered an explanation which was not taken up. The discussion continued.]

126. Rob: If you're subtracting a negative number, you are subtracting from the first total minus two of, so let's say you start with minus 2, right, you're taking away negatives. So, you're taking away 5 negatives from negative 2 . So, then, but, because you can only take 2 negatives away from negative 2, you have to take 3 other number and add them to the positive, put them as positives, so that's why it equals 3 .

[A student offered a new example, but Ms. Clarke redirected the students back to the prior example, pointing out that Rob used the chip board to describe the result and asking if students could similarly use the number line as justification.]

132. Dave: The reason it's 3, because when it's negative 2 and you're subtracting a negative number, it's the same as adding it.

133. T: Okay, so that's a different reason. How about on our number line? When we do negative 2 minus negative 5 , what are we finding here?

134. S: The difference.

135. T: The difference! Okay, what's the difference? What's the distance? Let's start with the distance. How many spaces are here?

136. S: Three!

137. T: Three! It's definitely three. Now, the question is, is it a positive three or a negative three.

138. S: Positive.

139. T: Why?

[Hubbub]

140. S: It's going to the right

This episode shows how students engaged in mathematical reasoning around integer addition and subtraction and how the number line and chip board models were used by the students and Ms. Clarke to describe the operations and to justify results. The episode shows how Ms. Clarke emphasised the need for students to more formally consider their prior work in the unit before developing more refined and comprehensive strategies for addition and subtraction.

The conjecture activity directly preceded the two remaining tasks in the instructional sequence. In the first remaining task, students described patterns in integer addition and subtraction (henceforth termed the Patterns task) by focusing on a number of examples that were intentionally varied in terms of the relative absolute values and the signs of the operands. In the first two enactments of this task, Ms. Clarke and Ms. Praeger struggled with the ways the examples were grouped for addition and subtraction. For both addition and subtraction, the problems were separated into two groups, one with like signs and the other with unlike signs. They found that the grouping focused students on the signs of the operands rather than on the underlying operations or strategies employed to generate solutions to the number sentences. Consequently, they changed the task by ungrouping the problems and having the students focus on arranging the 
problems by the strategies used to solve them. Ms. Clarke stated that "we really focused them again on this idea of strategy ... not problems that go together just because it's a positive minus a negative, but think about the strategy" (JI, March 25, 2010).

The last task in the sequence required that the students develop algorithms for addition and subtraction, which Ms. Clarke interpreted as generating strategies that covered all possible cases. Ms. Clarke stated that the goal was to avoid generating one procedure, like "keep-change-change" because "it's not all about funnelling big large ideas into one small procedure, because if that's all it's about again just show them that in the first place and have them practice it one hundred times" (VSI, August 28, 2009). Instead, she stated that the goal of developing the algorithms was to:

Help continue to support [the students'] understanding and learning so that they can make sense of the problems and realise that negative 3 plus negative 7 wouldn't be positive $10 \ldots$ and know why it's not, as opposed to just saying, "I can't remember the rule for what happens when I add two negatives." (JI, March 25, 2010)

In the latter part of the sequence described above, Ms. Clarke focused on eliciting and refining student conjectures, with the goal of helping students generate efficient yet sensible strategies for adding and subtracting integers. The task enactments showed how Ms. Clarke explicitly engaged students in the processes of refining their thinking and language with respect to integer operations and how she continually relied on the resources developed throughout the unit, such as the number line and chip board models.

In the discussion below, I articulate the three features of a local theory, the extent to which they were evident in Ms. Clarke's interviews and in the classroom episodes, and how her knowledge of the instructional sequence guided her practice. I conclude by describing the broader implications of the local theory with respect to the ways it impacted Ms. Clarke's ability to engage students' mathematical reasoning through challenging tasks.

\section{Discussion}

In this section, I discuss the nature of Ms. Clarke's local theory of instruction and how it organised her instruction in ways that engaged students with challenging tasks. First, she described a broad learning trajectory in terms of the sequence of tasks and how the sequence provided students opportunities to connect to their prior experiences, to develop the tools and experiences to subsequently make sense of integer addition and subtraction, to generate and refine conjectures, and ultimately to develop sensible and efficient strategies. It should be noted, however, that Ms. Clarke did not feel that the sequence determined a learning trajectory, but rather that the primary goal was to provide opportunities for sense making, acknowledging that the students had a range of sophistication with integer operations before and after the enactment of the sequence.

Second, Ms. Clarke noted a variety of resources that were influential in helping students to make sense of integer addition and subtraction. Notably, she emphasised the use of the chip board and number line models throughout the sequence, initially to help students to develop an understanding of integer operations and then as tools 
to describe and justify their emerging conjectures. Ms. Clarke also used number sentences as a key resource in helping students to note the connection between integer addition and subtraction. She initially emphasised the development of number sentences to help the students to distinguish between a situation involving temperature change and the computation used to find the temperature change. This allowed students to develop multiple number sentences to describe the same situation, and the differences between these number sentences focused the classroom discussion on the relationship between integer addition and subtraction. Finally, Ms. Clarke identified and used the students' own conjectures as resources in developing a collective understanding of integer addition and subtraction.

Third, Ms. Clarke described the processes by which students developed an understanding of integer addition and subtraction. She described the need to "mess around" with models and with integer operations, alluding to the necessity of engaging in pre-formal experiences that would serve as a "foundation" for subsequent work in the sequence. She described the need to develop resources that would ground students' actions and ultimately their conjectures. She stated, for example, that one of her goals in the unit was "this idea of giving kids facility with operations with integers but grounding that facility with operations in models that they can refer to" (VSI, June 4, 2008). Finally, she described the need to continually reflect on and refine language as a key process to developing understanding.

Ms. Clarke's knowledge of the instructional sequence informed how she enacted the sequence. She adapted tasks over the years to better establish and utilise the resources in the instructional sequence and to provide greater opportunities for students to build from their own reasoning. I briefly discuss three examples of task adaptations that illustrate how Ms. Clarke's knowledge informed her use of the materials in ways that enhanced the opportunities for students to engage in mathematical reasoning from challenging tasks. First, the adaptation of the Temperature Change task was designed to focus on the development of number sentences whose differences focused the discussion on integer operations rather than on simply solving the problem. This change helped to provoke discussions early in the sequence around the connection between addition and subtraction. Second, the adaptation of the Patterns task was designed to focus students on the operations used to solve the number sentences rather than on the more superficial characteristic of whether the operands had different signs. Ms. Clarke and Ms. Praeger felt that this was a more productive focus in light of the development of algorithms that followed and in light of the variety of conjectures the students had developed previously. This adaptation helped students to observe a variety of possible ways to group the problems, each way related to some characteristic of integer operations, including but not limited to differences in signs. Third, the task in which students developed algorithms was adapted in two ways. First, the problem in the student text appeared as part of a series of related questions in the Patterns task. Ms. Clarke and Ms. Praeger realised that it was premature to develop algorithms without more explicit support, given the complexity of developing comprehensive and sensible strategies and given the formative nature of students' thinking evident in the conjectures discussion. So, they had students write drafts of algorithms which were then shared in small groups. In the spring 2010 enactment, they added a new adaptation, which was to have each group write a collective final draft of an algorithm, which provided 
a new opportunity for negotiation, sense making, and collective formalisation. These adaptations emerged from the teacher's knowledge based in prior enactments of how task design and the resources in those tasks influenced the development of student learning. Furthermore, the adaptations provided students increased opportunities for sense making, for generating and reflecting on conjectures, and for refining and formalising their language and their strategies.

\section{Implications}

The biggest implication of this study is that Ms. Clarke developed her local theory by enacting challenging curriculum materials and by observing how students engaged with tasks from the materials. Her ability to make sense of student reasoning in specific tasks developed concurrently with her ability to adapt tasks and her understanding of how student thinking developed as a result of engaging with an instructional sequence. These facets of her practice and knowledge developed as a result of enacting the instructional sequence multiple times. On several occasions across the interviews, Ms. Clarke cited the importance of enacting the curriculum materials in order to understand them, even though she had attended curriculum-specific professional development prior to teaching the unit. Ms. Clarke stated that the first time through the unit she did not know what to anticipate. She stated that "the first time ... it's really about solving the problem ... we didn't know what ... to draw out of solving the problem, like 'what's the big idea, what's the goal, what do we need to ... help the kids notice?'” (JI, March 25, 2010). Ms. Clarke developed her knowledge through close observation of student thinking, as evident in the interviews, and refined that knowledge through collaboration and subsequent adaptations that reflected her new conjectures about student learning in a domain, much like the "testable conjectures" noted by diSessa and Cobb (2004). The "local" nature of theory is reflected in the limited range of who it impacted. Notably, Ms. Clarke's knowledge was mostly confined to her interactions with the students and with Ms. Praeger, though it likely informed how she conducted professional development around the Accentuate the Negative unit.

The design of the materials, particularly the high frequency of challenging tasks, the consistent press for explanation in the written tasks, the inclusion of multiple models and representations, and the opportunities for students to engage with a concept repeatedly before formalisation, likely contributed to the development of Ms. Clarke's knowledge. An important conjecture for future research is whether Ms. Clarke could develop a similar understanding of an instructional sequence from more conventional curriculum materials. The design of the materials, however, was "brought to life" by Ms. Clarke in a way that was unusually focused on student reasoning, suggesting that her beliefs about the teaching and learning of mathematics also played a role. Furthermore, most of the teachers observed in the broader study did not display the understanding of instructional sequences in the way that Ms. Clarke did, suggesting that the design of the materials, though helpful, does not by itself lead to the development of robust teacher knowledge. 
A last point concerns the nature of the context in which this study was situated. Certainly, Ms. Clarke is an exceptional case, in terms of her experiences, her beliefs about engaging students in sense-making activities, and the resources to which she had access. Such exceptional cases, however, can shed insight into processes that might not otherwise be revealed, processes that can lead to developing the most relevant kinds of teacher knowledge. In this case, the processes in which Ms. Clarke engaged helped her to develop the knowledge of how to use challenging tasks to elicit and build from student reasoning. Future research needs to investigate whether similar processes can be provoked in other contexts and whether these processes, and the resources associated with such processes, are necessary conditions for teachers to engage students with challenging tasks.

Acknowledgements I would like to thank the anonymous reviewers for their substantial and helpful feedback on earlier versions of this manuscript. This research was supported in part by the U.S. National Science Foundation under grant No. DRL-0746573. The opinions expressed herein are those of the author and do not necessarily reflect the views of the National Science Foundation.

\section{References}

Cai, J., Moyer, J. C., Wang, N., \& Nie, B. (2009). Learning from classroom instruction in a curricular content: An analysis of instructional tasks. Paper presented at the 31 st annual meeting of the North American Chapter of the International Group for the Psychology of Mathematics Education, Atlanta, GA: Georgia State University.

Carpenter, T. P., Blanton, M. L., Cobb, P., Franke, M. L., Kaput, J., \& McClain, K. (2004). Scaling up innovative practices in mathematics and science (Research report). Madison: National Center for Improving Student Learning and Achievement in Mathematics and Science.

Cobb, P., Confrey, J., diSessa, A., Lehrer, R., \& Schauble, L. (2003). Design experiments in education research. Educational Researcher, 32(1), 9-13.

Cobb, P., Zhao, Q., \& Dean, C. (2009). Conducting design experiments to support teachers' learning: A reflection from the field. Journal of the Learning Sciences, 18(2), 165-199.

Collopy, R. (2003). Curriculum materials as a professional development tool: How a mathematics textbook affected two teachers' learning. The Elementary School Journal, 103(3), 287-311.

Confrey, J., Strutchens, M. E., Battista, M., Smith, M. S., King, K. D., Sutton, J. T., et al. (2008). Situating research on curricular change. Journal for Research in Mathematics Education, 39(2), 102-112.

diSessa, A., \& Cobb, P. (2004). Ontological innovation and the role of theory in design experiments. Journal of the Learning Sciences, 13(1), 77-103.

Gess-Newsome, J. (1999). Pedagogical content knowledge: An introduction and orientation. In J. GessNewsome \& N. G. Lederman (Eds.), Examining pedagogical content knowledge: The construct and its implications for science education (pp. 3-17). Boston: Kluwer Academic Publishers.

Gravemeijer, K. (1994). Educational development and developmental research in mathematics education. Journal for Research in Mathematics Education, 25(5), 443-471.

Gravemeijer, K. (2004). Local instruction theories as means of support for teachers in reform mathematics education. Mathematical Thinking and Learning, 6(2), 105-128.

Grossman, P. L. (1990). The making of a teacher: Teacher knowledge and teacher education. New York: Teachers College Press.

Hiebert, J., Gallimore, R., Garnier, H., Givvin, K. B., Hollingsworth, H., Jacobs, J., et al. (2003). Teaching mathematics in seven countries: Results from the TIMSS 1999 Video Study. Washington: National Centre for Education Statistics, U.S. Department of Education.

Hill, H., Ball, D. L., \& Schilling, S. (2008). Unpacking pedagogical content knowledge: Conceptualizing and measuring teachers' topic-specific knowledge of students. Journal for Research in Mathematics Education, 39(4), 372-400.

Hill, H., Rowan, B., \& Ball, D. L. (2005). Effects of teachers' mathematical knowledge for teaching on student achievement. American Educational Research Journal, 42(2), 371-406. 
Lampert, M. (1990). When the problem is not the question and the solution is not the answer: mathematical knowing and teaching. American Educational Research Journal, 27(1), 29-63.

Lappan, G., \& Phillips, E. (2009). A designer speaks. Educational Designer, 1(3). Retrieved from http://www. educationaldesigner.org/ed/volume1/issue3/article11

Lappan, G., Fey, J. T., Fitzgerald, W. M., Friel, S. N., \& Phillips, E. D. (1998). Connected Mathematics. Palo Alto: Dale Seymour Publications.

Lappan, G., Fey, J. T., Fitzgerald, W. M., Friel, S. N., \& Phillips, E. D. (2006). Connected mathematics 2. Boston: Prentice Hall.

Lewis, C., Perry, R., \& Murata, A. (2006). How should research contribute to instructional improvement? The case of lesson study. Educational Researcher, 35(3), 3-14.

Magnusson, S., Krajcik, J., \& Borko, H. (1999). Nature, sources and development of pedagogical content knowledge for science teaching. In J. Gess-Newsome \& N. G. Lederman (Eds.), Examining pedagogical content knowledge: The construct and its implications for science education (pp. 133-144). Boston: Kluwer Academic Publishers.

Remillard, J. T., \& Bryans, M. B. (2004). Teachers' orientations toward mathematics curriculum materials: Implications for teacher learning. Journal for Research in Mathematics Education, 35(5), 352-388.

Schoenfeld, A. (2006). What doesn't work: The challenge and failure of the What Works Clearinghouse to conduct meaningful reviews of studies of mathematics curricula. Educational Researcher, 35(2), 13-21.

Shulman, L. (1986). Those who understand: Knowledge growth in teaching. Educational Researcher, 15 (2), 4-14.

Simon, M., \& Tzur, R. (1999). Explicating the teachers' perspective from the researcher' perspectives: Generating accounts of mathematics teachers' practice. Journal for Research in Mathematics Education, 30(3), 252-264.

Stein, M. K., Grover, B. W., \& Henningsen, M. A. (1996). Building student capacity for mathematical thinking and reasoning: An analysis of mathematical tasks used in reform classrooms. American Educational Research Journal, 33(2), 455-488.

Stylianides, G. J. (2009). Reasoning-and-proving in school mathematics textbooks. Mathematical Thinking and Learning, 11(4), 258-288.

Sullivan, P., Clarke, D., \& Clarke, B. (2009). Converting mathematics tasks to learning opportunities: An important aspect of knowledge for mathematics teaching. Mathematics Education Research Journal, 21(1), 85-105.

TERC. (1998). Investigations in Number, Data, and Space. Menlo Park: Dale Seymour.

Van den Heuvel-Panhuizen, M. (2003). The didactical use of models in realistic mathematics education: An example from a longitudinal trajectory on percentage. Educational Studies in Mathematics, 54, 9-35.

Van den Heuvel-Panhuizen, M. (2008). Learning from "Didactikids:" An impetus for revisiting the empty number line. Mathematics Education Research Journal, 20(3), 6-31.

Vincent, J., \& Stacey, K. (2008). Do mathematics textbooks cultivate shallow teaching? Applying the TIMSS video study criteria to Australian eighth-grade textbooks. Mathematics Education Research Journal, 20(1), 82-107. 